02

\title{
Перенос энергии электронного возбуждения между молекулами красителей, адсорбированных в одномерных фотонных кристаллах
}

\author{
(С) Ю.А. Строкова, С.Е. Свяховский, А.М. Салецкий \\ Московский государственный университет им. М.В. Ломоносова, Физический фракультет, \\ 119991 Москва, Россия \\ ฯ e-mail:sam@physics.msu.ru
}

Поступила в редакцию 31.03.2018 г.

\begin{abstract}
Экспериментально исследован перенос энергии электронного возбуждения между молекулами кумарина 7 (донор) и родамина Б (акцептор) в одномерных фотонных кристаллах на основе окисленного мезопористого кремния и в аналогичной матрице, не обладающей свойствами фотонного кристалла. По тушению флуоресценции донора и по сенсибилизированной люминесценции акцептора определены эффективности переноса возбуждения между молекулами донора и акцептора. Установлено увеличение эффективности переноса энергии электронного возбуждения в фотонном кристалле по сравнению с пористым кремнием.
\end{abstract}

DOI: $10.21883 /$ OS.2018.08.46360.94-18

\section{Введение}

Процессы переноса энергии электронного возбуждения (ПЭЭВ) применяются в многочисленных приложениях, таких как светоизлучающие и светособирающие устройства на основе полупроводниковых наноструктур [1], в биосенсорах [2], во флуоресцентной микроскопии для исследования клеток [3]. Поэтому ПЭЭВ широко исследуется как теоретически [4,5], так и экспериментально [6,7]. При этом проблемы ПЭЭВ в молекулах в однородных средах довольно хорошо изучены, а в системах с ограниченной геометрией (пористые матрицы, коллоиды, мицеллы и др.) изучены менее детально, несмотря на то, что в пористых системах эффективность энергообмена между адсорбированными молекулами изменяется и наблюдается размерный эффект такой эффективности $[8,9]$.

Как известно, эффективность ПЭЭВ зависит от расстояния между люминофорами и критического радиуса переноса энергии, который в свою очередь определяется перекрытием спектров излучения донора и поглощения акцептора, взаимной ориентацией диполей донора и акцептора, показателем преломления среды. Эффективность ПЭЭВ обычно исследовалась в зависимости от расстояния между активными молекулами в конденсированных средах с постоянным показателем преломления, а в системах с изменяющимся показателем преломления таких исследований очень мало. В связи с этим становится актуальным изучение ПЭЭВ в фотонных кристаллах (ФК), показатель преломления которых периодически изменяется в одном, двух или трех направлениях с периодом порядка длины волны. Характерной особенностью ФК является наличие фотонной запрещенной зоны (ФЗ3) - спектрального интервала, внутри которого локальная плотность фотонных мод (ФМ) равна нулю, а по его краям резко возрастает.

К настоящему моменту опубликовано небольшое число работ, посвященных экспериментальному исследова- нию ПЭЭВ между люминофорами внутри трехмерных ФК [10-12]. В этих работах показано, что в случае, когда Ф33 перекрывается со спектром излучения донора, эффективность ПЭЭВ в ФК выше, чем в средах, не обладающих свойствами ФК, или чем в ФК, ФЗ3 которых не перекрывается со спектром излучения донора. Однако для одномерных ФК подобные исследования не проводились.

ФК на основе окисленного мезопористого кремния (ПК) объединяют свойства как ФК, так и пористых структур с ограниченной геометрией и представляют интерес в качестве матрицы для молекул, влияющей на процесс переноса энергии между ними. Спектральные характеристики и оптические свойства таких структур в последнее время активно изучаются [13]. Целью настоящей работы является исследование ПЭЭВ между сложными молекулами в одномерных ФК на основе окисленного ПК и сравнение с аналогичными процессами в окисленном ПК без ФЗ3.

\section{Материалы и методы}

В исследовании использовались образцы одномерного ФК на основе окисленного ПК с переменным диаметром пор и образцы окисленного ПК с постоянным диаметром пор. Толщина образцов измерялась с помощью оптического микроскопа по срезу. Толщина используемого ФК составляет $111.42 \pm 0.14 \mu \mathrm{m}$, ПК $-158.1 \pm 0.8 \mu \mathrm{m}$. Средний диаметр пор ФК и ПК составляет $30 \mathrm{~nm}$. Диаметр пор определялся соответствующими условиями изготовления образцов. Более подробно методика приготовления образцов описана в [14].

Спектры пропускания образцов измерялись на спектрофотометре „СОЛАР“ РВ2201 (СОЛАР, Белоруссия). Удельная поверхность образца ФК была измерена методом сорбции газов и равняется $208 \mathrm{~m}^{2} / \mathrm{g}$. 
Для исследования ПЭЭВ была выбрана пара красителей Кумарин 7 (К7 - донор) и Родамин Б (РБ акцептор). Адсорбция молекул красителей на образцы осуществлялась из этанольных растворов смеси красителей $($ К $7+$ РБ). Концентрация К7 в растворах была равна $4 \cdot 10^{-5} \mathrm{~mol} / 1$, переменная концентрация акцептора РБ - от $1.33 \cdot 10^{-4}$ до $1 \cdot 10^{-3} \mathrm{~mol} / \mathrm{l}$. Концентрация К7, малая по сравнению с концентрацией РБ, была выбрана с целью исключить миграцию энергии по донорам и обратный перенос энергии от акцептора к донору. Образец погружался в раствор и высушивался.

В связи с тем, что образцы ФК и ПК отличались пористостью (эффективная пористость ФК составляет $51 \%$, а пористость ПК $-53 \%$ ) при описании ПЭЭВ в твердых образцах определялась поверхностная концентрация молекул. Для этого после измерений образцы выдерживались в известном объеме этанола. По оптической плотности вторичных растворов определено количество вещества красителя, адсорбированного в образце. Поверхностная концентрация красителя в образце определялась по формуле: $C_{S}=\frac{v N_{A}}{m S}$, где $v-$ количество вещества во вторичном растворе, $N_{\mathrm{A}}$ - число Авогадро, $m$ - масса образца, $S$ - площадь поверхности, определенная методом сорбции газов $\mathrm{N}_{2}$-BET.

Спектры люминесценции красителей в ФК и ПК измерялись в геометрии на отражение при углах освещения и регистрации люминесценции, равных $0^{\circ}$ по отношению к нормали к поверхности. Измерения проводились с помощью приставки к спектрофлуориметру „СОЛАР“ СМ2203 (СОЛАР, Белоруссия). Длина волны возбуждения $436 \mathrm{~nm}$ была выбрана с учетом того, что поглощение акцептора на этой длине волны мало. Суммарное поглощение красителей на длине волны возбуждения не превышает 0.02 , что позволило не учитывать эффект внутреннего фильтра.

\section{Результаты и их обсуждение}

На рис. 1 приведены спектральные характеристики образцов ФК и ПК и используемых красителей. Спектр пропускания для ФК (кривая 5) имеет нуль при длинах волн $500-535 \mathrm{~nm}$, в то время как для ПК в этой области спектра коэффициент пропускания равен $83 \%$ и практически не изменяется. На рис. 1 (кривые 1-4) представлены нормированные на максимум спектры поглощения $(1,3)$ и излучения $(2,4)$ выбранных донорных и акцепторных красителей.

Эффективность ПЭЭВ характеризуется так называемым критическим радиусом переноса (теоретическое значение):

$$
R_{0}^{6}=\frac{9000 \ln (10) \kappa^{2} Q_{D}}{128 \pi^{5} N_{\mathrm{A}} n^{4}} J,
$$

где $\kappa^{2}-$ ориентационный фактор $\left(\kappa^{2}=0.84 \times 2 / 3\right.$ для случая неподвижных молекул в твердых раствоpax), $Q_{D}$ - квантовый выход флуоресценции донора в отсутствие акцептора, $n-$ показатель преломления

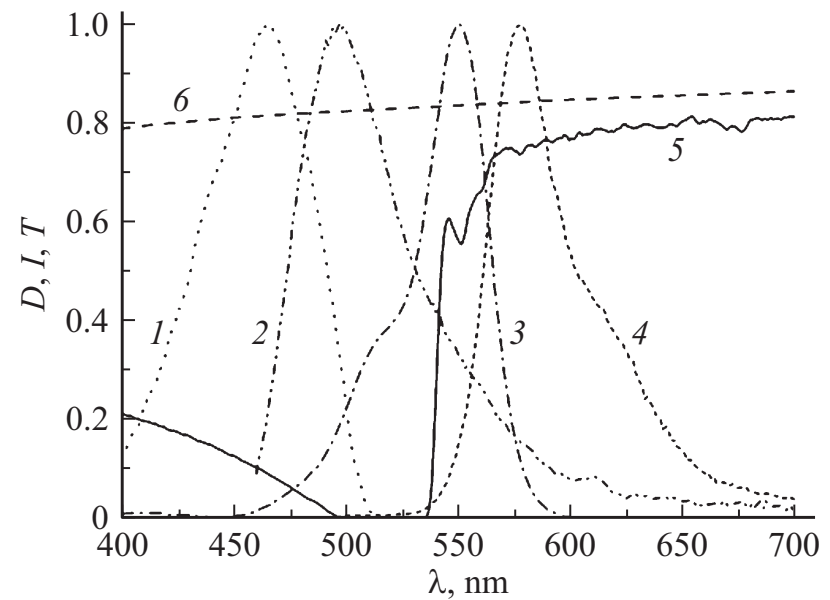

Рис. 1. Спектры поглощения $D(1,3)$, флуоресценции $I(2,4)$, и пропускания $T(5,6)$ для К7 $(1,2)$, РБ $(3,4)$, ФК (5) и ПК $(6)$ (кривые 1, 2, 3, 4 нормированы на максимальное значение).

среды на частоте ПЭЭВ, $J$ - интеграл перекрытия, рассчитываемый по формуле

$$
J=\int_{0}^{\infty} F_{D}(\lambda) \cdot \varepsilon_{A}(\lambda) \lambda^{4} d \lambda,
$$

где $F_{D}(\lambda)-$ нормированный на единичную площадь спектр люминесценции донора, $\varepsilon_{A}(\lambda)-$ молярный десятичный коэффициент экстинкции акцептора.

В ФК происходит вариация показателя преломления образца. В этой связи вычисление теоретического значения $R_{0}$ становиться некорректным, поэтому для характеристики эффективности ПЭЭВ в исследованных системах мы определили значения интегралов перекрытия $J$. Значения $J$ для этанольных растворов К7 + РБ равен $2.05 \cdot 10^{15}$, для ПК $-2.48 \cdot 10^{15}$ и для ФК $7.96 \cdot 10^{15} \mathrm{M}^{-1} \mathrm{~cm}^{-1} \mathrm{~nm}^{4}$. Увеличение интеграла перекрытия для образцов ПК вызвано небольшим смещением спектров и изменением формы спектра люминесценции К7 по сравнению с раствором. Для образцов ФК $J$ значительно больше и обусловлено перераспределением энергии в спектрах излучения донора и поглощения акцептора ввиду наличия $\Phi 33$, что указывает на увеличение эффективности ПЭЭВ между молекулами в ФК по сравнению с образцами ПК.

Для анализа ПЭЭВ были измерены спектры люминесценции донор-акцепторной пары $($ К $7+$ РБ $)$ для различных концентраций РБ, а также отдельно спектры К7 и РБ в ПК и ФК. Измеренные спектры люминесценции К7 и РБ в ФК и ПК представлены на рис. 2 и 3 соответственно.

Из сравнения спектров К7 в ФК и ПК (кривые 1 на рис. 2,3 ) следует, что в спектре К7 в ФК появился провал, обусловленный наличием $\Phi 33$, и усиление люминесценции в области длинноволнового края Ф3З. В целом представленные спектры (кривые 3,4,5 на 


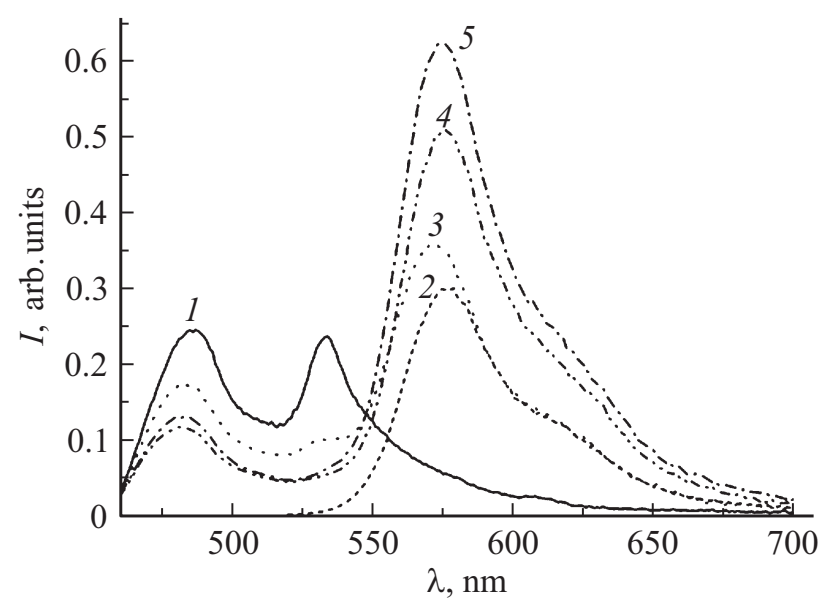

Рис. 2. Спектры люминесценции К7 (кривая 1), РБ с концентрацией $7.6 \cdot 10^{-4} \mathrm{~mol} / \mathrm{l}$ (кривая 2), К7 + РБ при различных концентрациях РБ в ФК. Концентрации РБ: 3 $2.2 \cdot 10^{-4} \mathrm{~mol} / 1,4-5.4 \cdot 10^{-4} \mathrm{~mol} / 1,5-6.4 \cdot 10^{-4} \mathrm{~mol} / \mathrm{l}$.

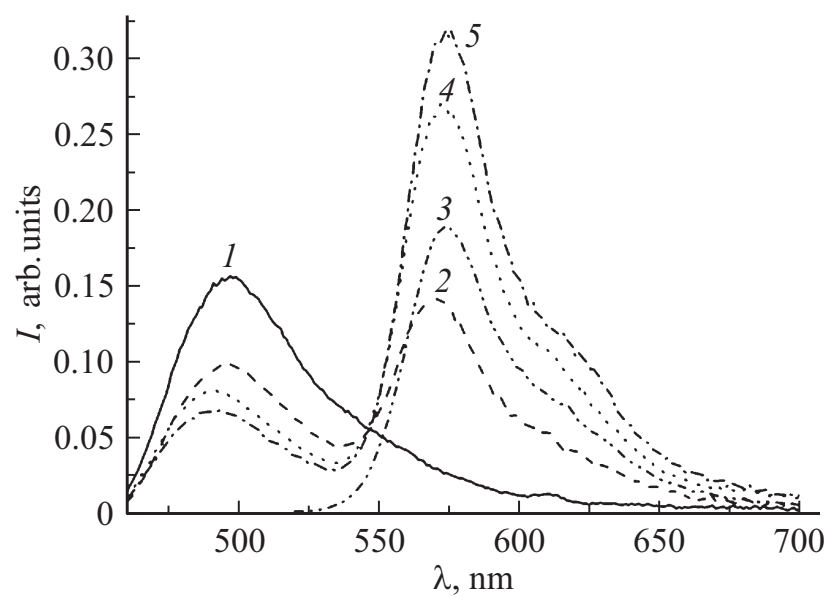

Pис. 3. Спектры люминесценции К7 (кривая 1), РБ с концентрацией $5.5 \cdot 10^{-4} \mathrm{~mol} / 1$ (кривая 3) и К7 + РБ при различных концентрациях РБ в ПК. Концентрации РБ: 2 $1.3 \cdot 10^{-4} \mathrm{~mol} / \mathrm{l}, 4-3.1 \cdot 10^{-4} \mathrm{~mol} / 1,5-5.0 \cdot 10^{-4} \mathrm{~mol} / \mathrm{l}$.

рис. 1 и кривые 2, 4, 5 на рис. 2) однозначно показывают, что с увеличением концентрации акцептора происходит тушение флуоресценции донора вместе с усилением излучения акцептора, превышающим собственную флуоресценцию РБ при возбуждении на длине волны $436 \mathrm{~nm}$. Это указывает на увеличение передачи энергии от донора к акцептору.

Поскольку в зависимости от ориентации диполя молекулы и его координаты (и длины волны излучения) внутри ФК изменяется локальная плотность ФМ, то спектр излучения молекул, внедренных в ФК, является неоднородно уширенным. Вследствие этого люминесценция К7 в присутствии акцептора в ФК в отличие от ПК тушится неравномерно на разных длинах волн. Наибольшее тушение наблюдается в интервале длин волн $529-540 \mathrm{~nm}$, совпадающем с длинноволновым пиком люминесценции
К7 и пиком спектра поглощения РБ (при нормальном падении света на образец), обусловленными высокой локальной плотностью ФМ на правом краю ФЗ3.

Наблюдается увеличение интенсивности свечения акцептора в ФК по сравнению с ПК во всем диапазоне исследованных концентраций РБ (рис. 2 и 3), т.е. в ФК наблюдается увеличение эффективности ПЭЭВ по сравнению с аналогичными системами в ПК. Эти результаты в основном объясняются уменьшением количества доступных ФМ для радиационного распада молекул донора в ФК по сравнению с однородной средой.

Для характеристики эффективности ПЭЭВ в исследованных системах были построены зависимости относительного квантового выхода флуоресценции $\frac{\eta}{\eta_{0}}$ К7 от концентрации РБ. Относительный квантовый выход флуоресценции донора определялся по формуле

$$
\frac{\eta}{\eta_{0}}=\frac{A(\lambda)}{A_{D}(\lambda)} \frac{I_{D}(\lambda)}{I_{D}^{0}(\lambda)}
$$

где $\eta, \eta_{0}-$ квантовый выход флуоресценции К7 в присутствии и отсутствие молекул акцептора в системе соответственно; $I_{D}(\lambda), \quad I_{D}^{0}(\lambda)$ - интегральные интенсивности люминесценции донора в присутствии и в отсутствие акцептора соответственно, $\frac{A(\lambda)}{A_{D}(\lambda)}-$ отношение поглощения донора в отсутствие акцептора к поглощению донора в присутствии акцептора.

Зависимость квантового выхода $\frac{\eta}{\eta_{0}}\left(C_{\text {РБ }}\right)$ К7 в $Ф$ ФК (кривая 1) и ПК (кривая 2) от концентрации РБ приведена на рис. 4. Из рис. 4 видно, что эффективность тушения флуоресценции К7 с ростом концентрации РБ как для ПК, так и для ФК увеличивается. Такое поведение $\frac{\eta}{\eta_{0}}\left(C_{\text {РБ }}\right)$ указывает на наличие ПЭЭВ между молекулами К7 и РБ. Сравнение кривых 1 и 2 на рис. 4 указывает, что эффективность тушения флуоресценции, а следовательно, и ПЭЭВ в ФК выше, чем в ПК в широком диапазоне концентраций РБ.

При ПЭЭВ увеличивается интенсивность флуоресценции акцептора. Для учета этого эффекта определим для различных концентраций РБ относительный показатель эффективности $E_{\mathrm{ef}}$, равный

$$
E_{\mathrm{ef}}=\frac{I_{A}}{I_{A}+I_{D}}
$$

где $I_{A}$ и $I_{D}-$ интегральные интенсивности люминесценции донора (К7) и акцептора (РБ), определенные в результате разделения спектров. Полученные зависимости показателя $E_{\text {ef }}$ для ФК и ПК от концентрации акцептора (РБ) приведены рис. 4 (кривые 3, 4).

Как следует из рис. 4 , показатель $E_{\text {ef }}$ растет с увеличением концентрации $C_{\text {РБ }}$ в донор-акцепторной паре. В целом значения эффективности для ФК находятся незначительно выше значений, полученных для ПК. Связано это с тем, что люминесценция акцептора в ФК в отличие от люминесценции донора изотропна и является усредненной по всем направлениям. 


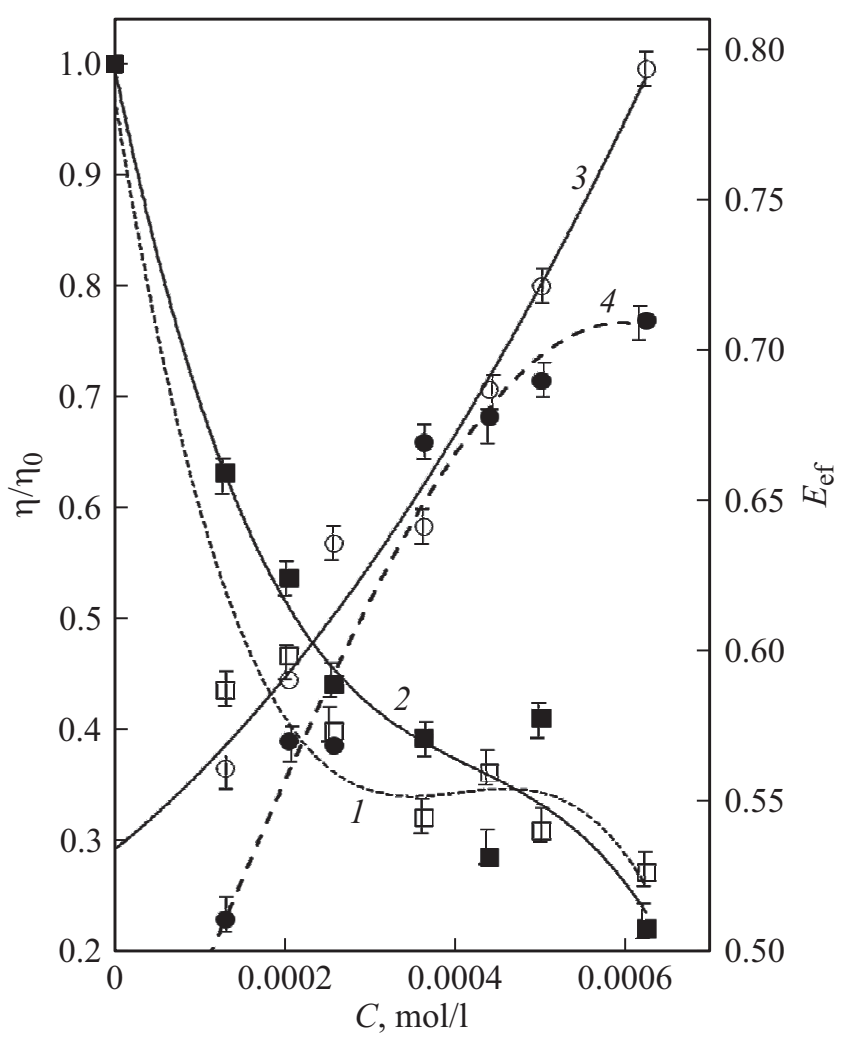

Рис. 4. Зависимости относительного квантового выхода $\frac{\eta}{\eta_{0}}$ донора $($ К7) $(1,2)$ и эффективности $E(3,4)$ от концентрации акцептора (РБ) для ФК $(1,3)$ и ПК $(2,4)$.

С дальнейшим увеличением концентрации показатель $E_{\text {ef }}$ для красителей в ФК и ПК растет медленнее, чем для красителей в растворе, что говорит о более плотной упаковке красителей в пористой структуре, чем в растворе.

\section{Заключение}

В работе представлены результаты исследования процессов переноса энергии электронного возбуждения между молекулами красителей в ПК и в одномерной фотонно-кристаллической пленке. Экспериментально определены эффективности переноса возбуждения между молекулами донора (Кумарин 7) и акцептора (Родамин Б) по тушению флуоресценции донора и по сенсибилизированной люминесценции акцептора. Установлены два механизма влияния Ф33 на межмолекулярный перенос энергии. Во-первых, неоднородное уширение спектра флуоресценции донора внутри ФК приводит к неравномерному тушению его флуоресценции на различных длинах волн в присутствии акцептора. Наибольшее тушение спектра происходит в интервале длин волн, совпадающих с максимумом спектра поглощения акцептора. Во-вторых, перераспределение энергии спектров флуоресценции донора и поглощения акцептора приводит к увеличению эффективности переноса энергии возбуждения в ФК по сравнению с ПК, что подтверждается зависимостью относительного квантового выхода донора от концентрации акцептора. На более высокую эффективность переноса возбуждения между молекулами в фотонно-кристаллической пленке по сравнению с ПК указывает и определенный экспериментально относительный показатель эффективности $E_{\mathrm{ef}}$.

Работа выполнена при поддержке Российского фонда фундаментальных исследований, грант № 16-02-01100.

\section{Список литературы}

[1] Demir H.V., Hernández Martínez P.L., Govorov A. // Understanding and Modeling Förster-type Resonance Energy Transfer (FRET). Springer Briefs in Applied Sciences and Technology. Singapore: Springer, 2017. 40 p.

[2] Shi J., Tian F., Lyu J., Yang M. // J. Mater. Chem. B. 2015. V. 3. N 35. P. 6989. doi 10.1039/C5TB00885A

[3] Pietraszewska-Bogiel A., Gadella T.W.J. // J. Microscopy. 2011. V. 241. N 2. P. 111. doi 10.1111/j.1365-2818.2010.03437.x

[4] Bodunov E.N., Antonov Yu.A., Simões Gamboa A.L. // J. Chem. Phys. 2017. V. 146. P. 114102. doi 10.1063/1.4978396

[5] Бодунов Е.Н., Берберан-Сантуш М.Н. // Опт. и спектр. 2015. T. 119. № 1. C. 25. doi 10.7868/S0030403415070053; Bodunov E.N., Berberan-Santos M.N. // Opt. Spectrosc. 2015. V. 119. N 1. P. 22. doi 10.1134/S0030400X1507005X

[6] Булаков Д.В., Салецкий А.М. // Опт. и спектр. 2008. Т. 104. № 3. C. 423; Bulakov D.V., Saletskĭ A.M. // Opt. Spectrosc. 2008. V. 104. N 3. P. 374. doi 10.1007/s11449-008-3010-9

[7] Пащенко В.З., Коновалова Н.В., Багдашкин А.Л., Горохов В.В., Тусов В.Б., Южаков В.И. // Опт. спектр. 2012. T. 112. № 4. C. 568; Paschenko V.Z., Gorokhov V.V., Tusov V.B., Bagdashkin A.L., Yuzhakov V.I., Konovalova N.V. // Opt. Spectrosc. 2012. V. 112. N 4. P. 519. doi 10.1134/S0030400X12040169

[8] Старокуров Ю.В., Летута С.Н., Пашкевич С.Н., Антропова Т.В., Гордеева Ю.А., Салецкий А.М. // Опт. и спектр. 2012. T. 114. № 1. C. 95. doi 10.7868/S003040341301025X; Starokurov Y.V., Gordeeva Y.A., Saletsky A.M., Letuta S.N., Pashkevich S.N., Antropova T.V. // Opt. Spectrosc. 2013. V. 114. N 1. P. 87. doi 10.1134/S0030400X13010256

[9] Afanasyev D.A., Ibrayev N.K., Saletsky A.M., Starokurov Y.V., Gun'ko V.M., Mikhalovsky S.V. // J. Luminesc. 2013. V. 136. P. 358. doi 10.1016/j.jlumin.2012.11.013

[10] Kedia S., Sinha S. // J. Phys. Chem. C. 2015. V. 119. N 16. P. 8924. doi 10.1021/jp512954p

[11] Kolaric B., Baert K., Auweraer M.V.D., Vallee R.A.L., Clays K. // Chem. Mater. 2007. V. 19. N 23. P. 5547. doi $10.1021 / \mathrm{cm} 0713935$

[12] Zou L., Sui N., Wang Y.H., Qian C., Ma Y.G., Zhang H.Z. // J. Luminesc. 2015. V. 158. P. 281. doi 10.1016/j.jlumin.2014.10.016

[13] Горелик В.С., Яшин M.M., Dongxuе Di, Guang Tao Fei // Опт. и спектр. 2018. Т. 124. № 2. С. 171. doi 10.21883/OS.2018.02.45519.177-17

[14] Svyakhovskiy S.E., Maydykovsky A.I., Murzina T.V. // J. Appl. Phys. 2012. V. 112. N 1. P. 013106. doi 10.1063/1.4732087 